\title{
Designing an Educator Toolkit for the Mobile Learning Age
}

Kevin Burden, The Faculty of Arts, Cultures and Education, The University of Hull, Hull, UK

Matthew Kearney, STEM Education Futures Research Centre, University of Technology Sydney (UTS), Sydney, Australia

\begin{abstract}
Mobile technologies have been described as 'boundary' objects which enable teachers and learners to transcend many of the barriers such as rigid schedules and spaces which have hitherto characterised traditional forms of education. However, educators need to better understand how to design learning scenarios which genuinely exploit the unique pedagogical affordances of mobile technologies rather than replicating existing patterns and modes of behaviour. This article describes the design and development of a mobile learning toolkit for educators to realise this vision. It presents the theoretical underpinnings for the toolkit and describes the development of different tools, instruments and resources. The main aim of the toolkit is to help teacher educators and teachers build knowledge and understanding of more diverse mobile pedagogical approaches.
\end{abstract}

\section{KEYWORDS}

Education Technology, m-Learning, Pedagogy, Teacher Education, Toolkit

\section{INTRODUCTION}

Mobile learning (m-learning) is considered in this paper as learning mediated by handheld devices such as smartphones and tablet computers (Schuler, Winters \& West, 2012). The wide range of capabilities of these technologies has created considerable interest amongst educators (Becker et al., 2016) who seek to explore their application for learning. However, recent research suggests teachers tend to default to traditional teaching practices when using mobile devices for pedagogical purposes, focusing on teacher-directed approaches and content delivery (Cochrane \& Antonczak, 2014; Kearney, Burden \& Rai, 2015). If transformative pedagogies are to be adopted, educators need to better understand how to design m-learning experiences which genuinely exploit the unique affordances of mobile technologies.

In teacher education, staff are engaging with mobile pedagogies, responding to the rapid adoption of m-learning in schools (Herrington, Ostashewski, Reid \& Flintoff, 2014; Newhouse, Cooper \& Pagram, 2015). The challenge for teacher educators is to model exemplary practices and facilitate pre-service teachers' (PSTs') ability to enhance their own mobile pedagogies. There is a need for teacher educators to support PSTs' learning through a wider range of m-learning activities, such as more in-situ learning contexts, greater consideration of student agency and more use of networked and virtual conversations to share practices beyond the immediate vicinity and access of external expertise (Burden \& Kearney, 2017). There is also a need for greater exemplification of how teacher educators use mobile devices to model and practise approaches relevant to K-12 teaching and learning (see for example, Naylor \& Gibbs, 2015). There is a shortage of pedagogical and theoretical models that can guide teacher educators in designing m-learning experiences, and a need to develop a shared 
language for describing emerging pedagogies (Herrington et al., 2014). Indeed, practical strategies are required that will support teacher educators in fully exploiting mobile learning (Baran, 2014).

This paper discusses the design and development of a mobile learning toolkit (http://www.

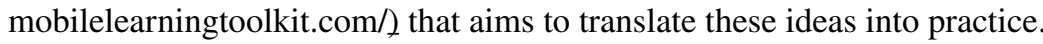

\section{BACKGROUND}

\section{Pedagogic Toolkits}

Pedagogic toolkits have been promoted as ideal resources for educators to become more engaged with new, challenging areas of teaching (Oliver \& Conole, 2000) particularly in the area of digital pedagogies. They typically focus on teachers' professional learning about designing pedagogyin the case of our toolkit, designing and implementing effective mobile pedagogies-providing resources and strategies ('tools') to support teachers in addressing pedagogical problems in their own teaching contexts. In this way, toolkits can be viewed as bringing "best practice within the reach of all practitioners in a usable format" (p. 36), and a conduit for professional engagement in new pedagogical domains.

Toolkits assume a 'just-in-time' approach and generally promote flexible engagement by the user, in contrast to more traditional, linear-structured manuals or cookbooks, and also distinct from more prescriptive, scaffolded digital templates and wizards that incorporate a 'just-in-case' approach (Conole \& Oliver, 2002). However, toolkits are more open-ended and adaptable than this type of template approach (Conole \& Fill, 2005), providing support to teachers beyond surface-level guidance.

The core element of educator toolkits is the theoretical underpinning. Hence, use of a pedagogic toolkit aims to support educators making theoretically-informed decisions about appropriate pedagogies. Any 'claims' in a pedagogic toolkit for teachers, such as claims of 'best practice' or 'good learning', can therefore be interpreted through the lens of the toolkit's underpinning theory. Apart from this foundational theoretical overview, other toolkit elements include strategies and mediating tools for the user to engage with the espoused theory.

\section{Examples of Toolkits Supporting Digital Pedagogies}

There has been a growing number of pedagogic toolkits designed and developed for supporting teachers' effective use of new and emerging learning technologies. Bowe and Winter (2014) discuss the development of their 'technology toolkit' for PSTs for supporting development of digital pedagogies. Their toolkit had a major focus on a selected set of teaching strategies incorporating educational technologies. Botha and Herselman (2015) described the design and application of a 'teacher tablet toolkit' for the professional development of rural teachers, enabling them to use mobile devices to support teaching and learning in their classrooms. The resulting toolkit focused on pragmatic pedagogical and technology knowledge, skills and practice-based experience. Simulation and game design were key themes. While Lim and Pannen (2012) designed a 'capacity building toolkit' to be used by teacher education institutions to build their capacity for developing PSTs' digital competencies. It provided a set of tools for institutions in the Asia Pacific region to conduct needs and situation analyses of the current state of ICT use in their teaching and administration; and aimed to support the development of institutions' strategic plans to build this capacity in their programs.

Other toolkits for teachers in the area of educational technology integration include toolkits for media and resource selection, evaluation and information management (Conole \& Oliver, 2002), and learning design (Conole \& Fill, 2005). Learning analytics was the focus of a toolkit designed and tested by Dyckhoff et al. (2012). They introduced 'eLAT', an exploratory Learning Analytics Toolkit supporting teachers' use of data to monitor and analyze their teaching activities. 


\section{PROCEDURES}

The toolkit that is the focus of this paper was designed as part of an EU funded project (see http:// mttep.eu), led by the University of Hull, UK. The multinational project team consisted of three school partners (in Germany, the Netherlands and Norway) and five university partners (in Australia, Germany, Norway and UK). All but one of the university partners were institutions of teacher education and were selected on the basis of their expertise and use of mobile learning with PSTs. Each of the three school partners had explored the use of mobile and tablet computers and were identified as being at the point of readiness to investigate more expansive and far reaching mobile learning approaches. In summary, the team was a transnational, heterogeneous partnership of educators and the development of the toolkit needed to encompass a broad and diverse range of particular interests and motivations.

\section{Toolkit Construction}

Toolkit development followed the main themes espoused by Conole and Oliver (2002) for developing pedagogic toolkits.

1. Assessment of Need by Practitioners: Each component of the m-learning toolkit was driven by a needs analysis from both teacher educators and teachers. For example, a needs analysis was conducted amongst 30 delegates (teachers and teacher educators) at one of our 2015 international conference workshops ${ }^{1}$ as to what type of app rubric (one of the numerous toolkit components) would be useful for educators, beyond what was currently available. Similarly, 68 educators from several countries were surveyed regarding their perceived needs for the online course component of the toolkit. The course's final core and elective topics were selected from this analysis.

2. An Explicit Theoretical Underpinning: We adopted a mobile pedagogical framework emerging from our own earlier work (Kearney, Schuck, Burden \& Aubusson, 2012) to inform the design of the m-learning toolkit elements.

3. Toolkit Specification: The m-learning toolkit was designed to be easy-to-use and to support practitioners' flexible use. Elements of the toolkit, such as the survey tool and online course, can easily be adapted by an institution to fit the user's context e.g. teacher education, school teacher mentoring.

4. Toolkit Refinements and Inclusion of User Defined Features Informed by User Trials: Each element of the m-learning toolkit was developed and refined through an ongoing, iterative process over the life of the project, as described in the next sub-section: 'Developing the toolkit elements'.

5. Build Shared Resources: The m-learning toolkit is organic in the sense that user-generated data will be used to populate and expand toolkit elements, for example, the app review database and the video case scenarios. In this way, users of the m-learning toolkit will generate and share materials for repurposing.

\section{DEVELOPING THE TOOLKIT ELEMENTS}

The toolkit elements were developed and refined through an iterative design-test-analyse-refine cycle (Kemmis \& McTaggart, 1988), to address the key question: What does a mobile learning toolkit for educators look like that aims to support their engagement with contemporary mobile pedagogies? Formative feedback fed into this cycle and leveraged opportunities to test and refine progressive iterations of the toolkit elements. Data was collected at international scholarly workshops, presentations and meetings from 2015 to 2017, including multiplier events ${ }^{2}$ hosted by the project in 2015 (50 participants) and 2016 (77 participants); workshops at several international educational technology conferences ${ }^{3}$ (approx. 30 delegates at each session); a research symposium (approx. 30 delegates in attendance) and poster at an international mobile learning conference ${ }^{4}$; two research 
seminars (approximately 20 scholars at each) at the authors' institutions in 2016; and six (internal) project meetings. The project multiplier events and project meetings had dedicated sessions (e.g. using focus groups) devoted to feedback on specific toolkit elements.

A variety of data was collected during these events, emphasising toolkit users' perspectives in the design process, and following general design guidelines based on constructivist theory (Willis, 2000). Data sources included verbal and written feedback from practising expert teachers from within and outside the project team (e.g. at the 'multiplier events' and workshops); verbal and written feedback from academics in Teacher Education (from within and outside the project team) and Software Engineering (e.g. for the app rubric development); verbal feedback from conference delegates and written feedback on academic papers ${ }^{5}$; trials with PSTs and school students (e.g. for the student survey development); and analysis of user documents (e.g. trialists' completed task surveys and rubrics). Various online facilities were used to gather feedback, including email, backchannels (e.g. using the online Zeetings platform) during conference and workshop presentations; online surveys (using university-based tools and Google Forms), online writing 'walls' (e.g. Padlet), widgets (for feedback on the interactive eBooks) and discussion fora (e.g. peer feedback from colleagues in our project's Slack platform). Strategies were used to promote collaborative critical reflection (Ghaye \& Ghaye, 1998) throughout the development cycles, taking into account a range of perspectives from pedagogical and m-learning experts within and outside of the project team. These discussions critiqued elements of the toolkit from a mobile pedagogical perspective and interrogated how well it aligned with the socio-cultural theory (Wertsch, 1991) underpinning this perspective (Kearney et al., 2012).

\section{THE TOOLKIT ELEMENTS}

Informed by the procedures described above, a toolkit prototype was designed incorporating six elements. At the core of the m-learning toolkit is a robust mobile pedagogical framework (Kearney et al., 2012) that underpins the design of the other components: A m-learning task survey (teacher and student versions), an app evaluation rubric, video-based exemplar cases, interactive e-books and an online course. These resources are tagged and matched to the mobile pedagogical framework, enabling users to interrogate the toolkit by the signature pedagogies of mobile learning.

\section{The Mobile Pedagogical Framework (iPAC)}

The theoretical underpinning for the toolkit is a validated mobile pedagogical framework developed by the authors and other colleagues (Kearney et al., 2012). Informed by sociocultural theory (Wertsch, 1991), it highlights three distinctive pedagogical features of m-learning: personalisation, authenticity and collaboration (or 'PAC'). How learners experience these distinctive characteristics is influenced by their use of 'time-space' (or context), as depicted in Figure 1.

The personalisation construct consists of the sub-constructs 'agency' and 'customisation'. High levels of personalisation would mean the learner is able to enjoy an enhanced degree of agency (Pachler, Bachmair \& Cook, 2009) and the flexibility to tailor both tools and activities, interacting with a strong sense of ownership of both the device (e.g. Gasparini, 2011) and the learning process. The authenticity construct privileges opportunities for in-situ, participatory learning (Radinsky, Bouillion, Lento \& Gomez, 2001). The sub-constructs of 'task', 'tool' and 'setting' focus on learners' involvement in rich, contextualised tasks, making use of tools in a realistic way, and driven by relevant real-life practices and processes. The collaboration construct captures the conversational, networked features of m-learning. It consists of 'conversation' and 'data sharing' sub-constructs, as learners engage in negotiated meaning-making, forging connections and interactions with peers, experts and the environment (Wang \& Shen, 2012). The mobile pedagogical framework provides a useful lens to explore how mobile technologies can leverage potentially transformational pedagogies in a range of formal and informal learning settings. 
Figure 1. A representation of our mobile pedagogical framework, (IPAC) comprising three distinctive features of mobile learning experiences (adapted from Kearney et al., 2012, p.8)

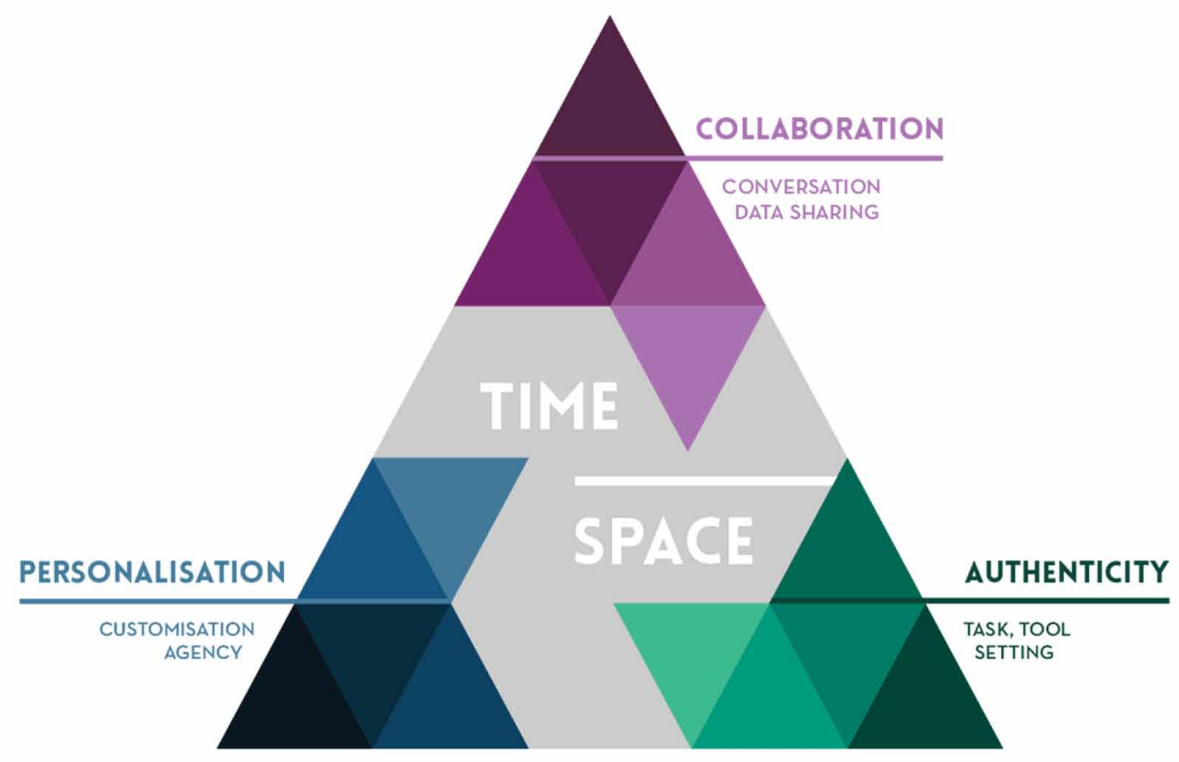

\section{The Mobile Learning Task Survey Tools (Teacher and Student Versions)}

The survey components of the toolkit contain a selection of online survey tools that educators can use in various ways to measure and evaluate their m-learning practices. It relies on self-reported data that participants provide that focus on a m-learning scenario they have recently implemented. The teacher version is used by educators to evaluate their own task, particularly their use of the distinctive mobile pedagogies. The student survey provides a perspective based on student voice (Campbell \& Groundwater-Smith, 2007), thereby triangulating the data from the teacher survey. The data generated from both the teacher and student versions of the survey is presented to teacher participants in the form of a polar chart, as shown by the sample report in Figure 2.

The teacher report allows teachers to compare their own responses (Figure 2a) with their students' responses (Figure 2b), providing an m-learning profile with guidance and suggestions for further professional development.

The development of the survey instrument was informed mainly by trials at the aforementioned international workshops, both multiplier events and (internal) project meetings. Feedback was received in relation to user-friendliness and basic aesthetics of the instrument and the teacher's report. Polar charts were preferred in the report over traditional bar charts which users found more difficult to interpret. Additional advice on 'development opportunities' was requested in the report, especially for teachers with 'weaker' task ratings, or ratings that were significantly different to their students' scores. Sample feedback included: 
Figure 2. Screenshot of the report generated for teachers after they and their students have completed the survey

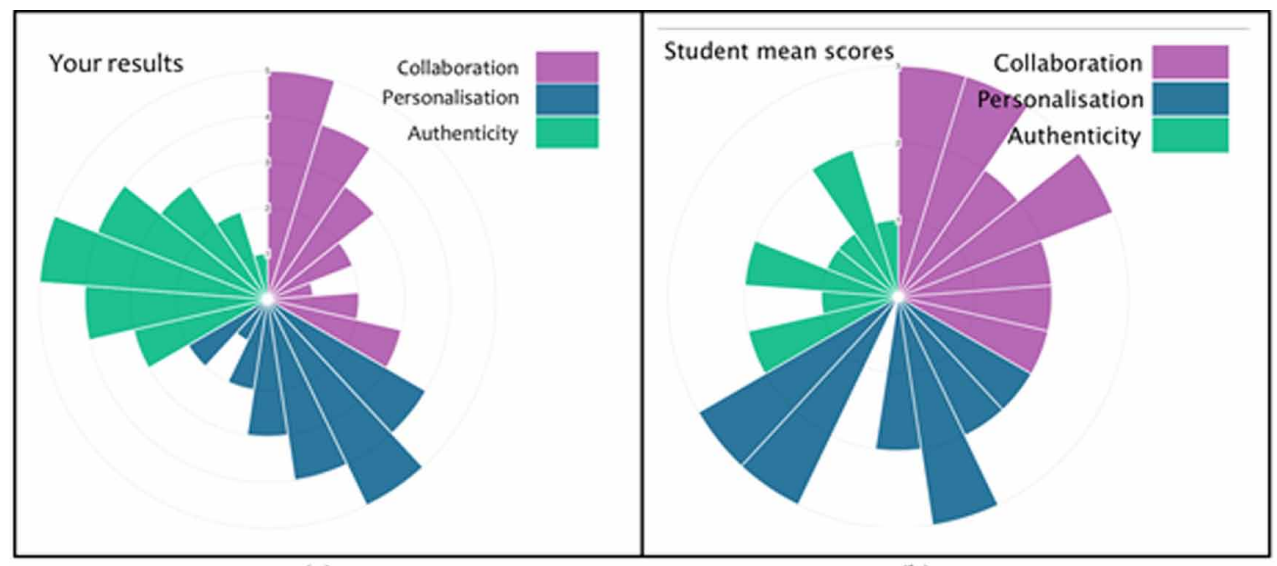

(a)

(b)

I would like to see some guidance on further development addressing weaker scores. So if I am low in personalisation then perhaps some links or tips would help" [participant from Norway multiplier event].

Some reference to development opportunities for results that were low or in conflict with student responses." [participant from Norway multiplier event].

Other ideas were received and acted upon, such as the suggestions (now written into toolkit guidelines) for surveys to be used by PSTs after campus-based 'mirco-teaching' scenarios, or after a school-based practicum task they have implemented. Language issues dominated the feedback on the student survey, with 21 out of 32 responses (Norway multiplier event) deeming the overall language in the items as not user-friendly for high school students.

\section{Video Scenario Matrix}

This toolkit component provides a selection of exemplar practice video scenarios depicting m-learning activities in a variety of disciplines and across a range of teacher education and school-based contexts. For each scenario, recommendations are included for particular tools and apps to support the activity.

These video cases illustrate and contextualise various dimensions of the iPAC framework, and aim to stimulate interest and pedagogical discussion amongst PSTs. Additional video case studies from outside the project partners have already been added to the matrix and it is anticipated the education community will supplement the project's existing resources with m-learning video exemplars of their own.

The development of the video cases was informed by trials at the project's 2016 multiplier event - including a dedicated session where both written and verbal feedback was elicited from all 77 participants, (internal) project meetings and by peer feedback from colleagues via the project's online communication platform. Feedback mainly related to 'user-friendliness' issues, such as the length of the video, or graphic design issues, such as legibility of text appearing on the videos. Peer feedback from project colleagues focused more on the content, for example, some videos were revised to focus just on one iPAC dimension rather than trying to include all three constructs. 


\section{App Evaluation Rubric}

Although educators are looking for advice and guidance on how to select and use discipline specific apps (e.g. Green, Hechter, Tysinger \& Chassereau, 2014) our analysis of teachers' background needs and previous research (Kearney et al., 2015) suggested educators tend to use more generic, 'content free' apps. Such apps are typically used by learners for more creative, 'constructive' purposes (Goodwin \& Highfield, 2013), for example to generate their own digital content. It was concluded that an app evaluation instrument that caters for both discipline-specific and more generic apps, was more sustainable and scalable in the longer term. Therefore, our toolkit contains an original app evaluation rubric to help teachers assess, select and use any type of educational app, with emphasis on the sociocultural aspects of the iPAC pedagogical framework.

Several iterations of the rubric were developed during the project. The main sources of feedback were: 1) five expert teachers from outside the project (online survey) in November 2016; 2) six academics in teacher education (in and outside of the project team) and two Software Engineering academics in December 2016 (via email); 3) project members at two project meetings in March 2016 and March 2017 (individual users, focus groups and using Padlet to collate responses); 4) two 'user trials' by PSTs at critical points of the rubric development. The first trial was conducted in August, 2016 by 45 postgraduate PSTs; the second trial of a more refined version of the instrument was conducted in early 2017 by 17 postgraduate PSTs.

The feedback informed a range of actions addressing 'user-friendliness' issues, such as provision of a link to a Youtube video to explain Goodwin and Highfield's (2013) app categories (relevant to one of the Background questions). Also, the two systems software academics gave feedback on the 'pop up notes' accompanying the rubric, suggesting relevant examples of 'app features' to facilitate more informed and confident responses by rubric users (see Figure 3).

Like the survey tool, there were numerous language issues raised in the feedback on beta versions of this rubric. Minor revisions were made to relevant items and the associated 'pop-up notes'.

\section{Online Course}

The toolkit includes access to an online course that brings together all of the various toolkit resources and exemplars in a twelve week course, enabling teacher educators and teachers to learn as part of an international network. The needs analysis influenced the platform and structure of the course (e.g. the choice of Google Sites as the main platform) and selection of the core and elective modules. The

Figure 3. Screenshot of the 'Collaboration' items in the online rubric. Feedback informed the 'pop up notes' that provide relevant sample app features to help users decide their ratings

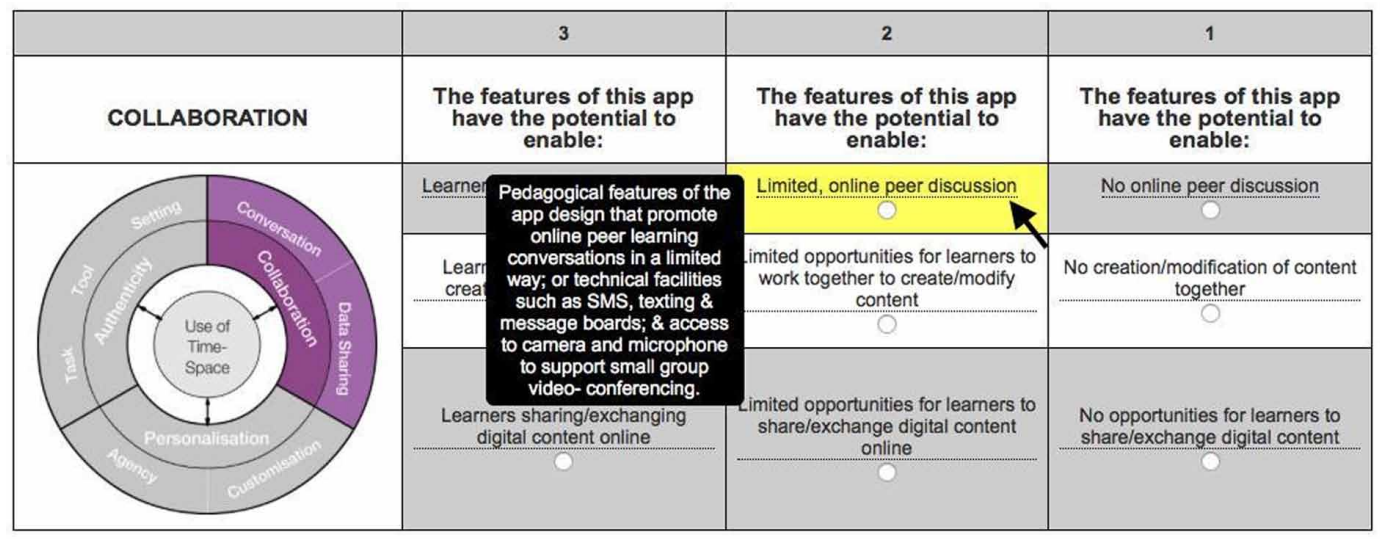


online course is also designed as a 'shell' type course that institutions can adopt and adapt to their particular contextual needs and settings.

Sources of feedback included (internal) project meetings and peer feedback from colleagues via the project's online communication platform. Apart from technical issues relating to the two delivery platforms, feedback relating to 'coherency' issues helped with standardisation across the course-such as consistent use of peer and self-assessment procedures in each module, and provision of links to the iPAC framework in all modules.

\section{Interactive eBooks}

The toolkit includes a series of three exemplar eBooks (see Figure 4) available via Apple's iBooks Store. These illustrate the use of mobile technologies in teacher education, emphasising how eBooks might be used, and with what impact.

The development of the three interactive eBooks was informed by focus groups at both multiplier events, including a dedicated session where both written feedback (via eBook widgets) and verbal feedback was elicited from all delegates, and peer feedback via (internal) project meetings and via the project's online communication platform. Examples of modifications included the addition of advanced organizers, shortening of text, and uploading of all videos to YouTube to decrease the eBooks' download time.

\section{Toolkit Structure}

In summary, Figure 5 shows an overview of the six components of the m-learning toolkit and their relationship with each other.

The toolkit has a non-linear structure in accordance with previous guidelines on toolkit design and construction (Conole \& Oliver, 2002). In this way, the toolkit caters for users with different agendas and goals, and of varying levels of expertise. The toolkit is organic in the sense that users will populate and make ongoing contributions to elements such as the app review database and the video case scenarios.

\section{DISCUSSION}

The toolkit for educators introduced in this paper reflects many of the features highlighted in the toolkit design literature, reviewed previously. However, it is the inherent flexibility and adaptability

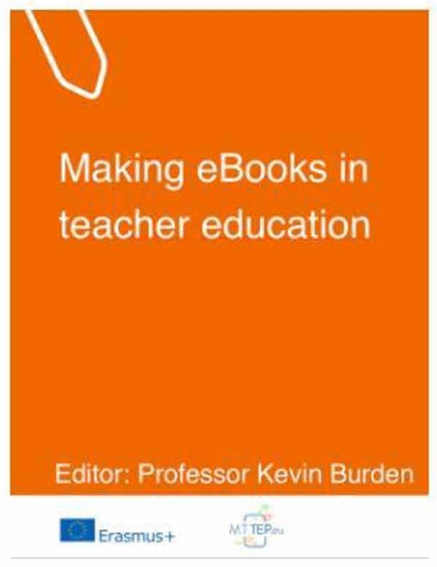

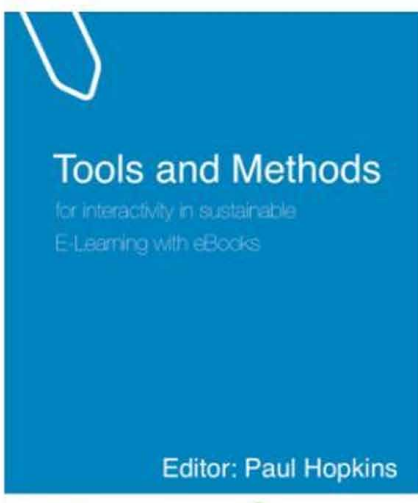

Erasmus+

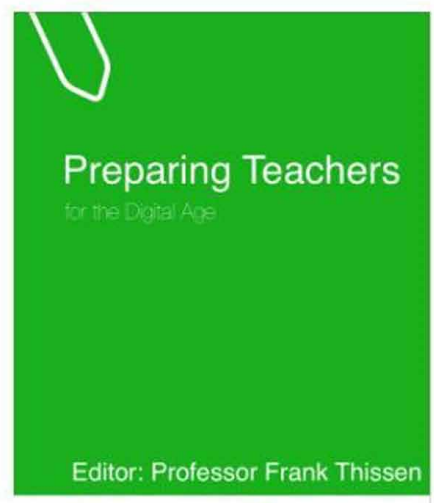

Erasmus+ 


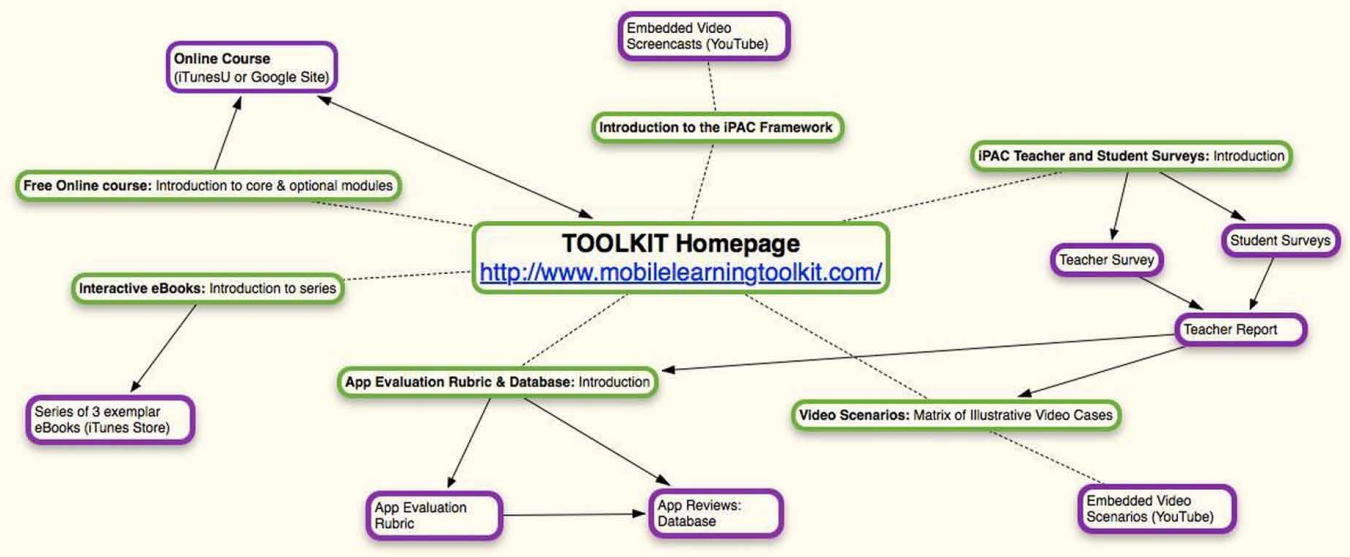

Colour CODES:

Green border: Online toolkit at http://www.mobilelearningtoolkit.com/

Purple border: External to Toolkit Website e.g. iTunesU

of the final toolkit that we examine in this final discussion section since these affordances are more problematic and worthy of further exploration.

The flexibility and responsiveness of toolkit design is a benefit for designers who seek to generate tools and exemplars that are constructivist and collaborative in nature since they encourage users to adapt and modify rather than replicate or use 'off the peg' exemplars. This is consistent with sociocultural theory since it recognises how a tool may be modified according to the ways it is used, and in turn, its design will influence how people may use it (Salomon \& Perkins, 1998).

Proponents of toolkits identify their inherent flexibility, adaptability and responsiveness to diverse contexts as the features that set them apart from templates and wizards, which are characterised as more determinist (Conole \& Oliver, 2002). Our experience of developing the mobile learning toolkit supports this interpretation. Since the toolkit was designed with a sociocultural theoretical underpinning, it encourages, but does not dictate, the creation of sympathetic exemplars and tools that emphasise shared understandings and construction of meaning. For example, the video case studies which are used to illustrate the iPAC framework in practice, do not offer a recipe of 'best practice' for using mobile technologies in teacher education, but rather they encourage the viewer to deconstruct these exemplars using the iPAC framework, in order to identify underlying principles and meanings that might be adapted for use in their own context.

The flexible nature of the toolkit enabled partners from a diverse range of geographical and cultural backgrounds to work collaboratively in order to contribute their own vignettes under the broad socio-cultural canvas of the iPAC framework. More directive approaches may have inhibited or prevented this kind of collaboration amongst partners and it is anticipated the toolkit will encourage a similar level of diversity when it is adopted by end-users.

It is difficult or impossible to predict which tools and instruments end-users will utilise or in what sequence. However, we have anticipated this varied, unpredictable usage of the toolkit can best be designed for by the promotion of broad theoretical principles rather than prescriptive user-guides. Hence our mobile pedagogical (iPAC) framework is instantiated across each of the individual elements of the toolkit. Indeed, the procedures described in this paper have focused on the individual toolkit 
elements that were tested and refined extensively during the development phases. The holistic use of the toolkit remains to be tested and this future evaluation may shed more light on how end users adopt it.

Finally, the toolkit is deliberately designed to be adaptable for use in diverse settings and contexts. It is anticipated that institutions of teacher education, teaching schools, and any institution involved in the field of continuing staff professional development will be interested in using the toolkit but not necessarily in its project instantiation, or in its entirety. This partly explains the modular design of the toolkit which can be de-coupled and adapted at a more granular level than a template or wizard would allow.

\section{CONCLUSION}

There is a burgeoning interest in m-learning approaches in teacher education and consequently academics are involved in sharing and exchanging information on research and potential uses of mobile technologies through working groups and professional learning communities (e.g. Schuck, Aubusson, Kearney \& Burden, 2013). This paper describes the design and development of a mobile learning toolkit for teacher educators and teachers that endeavours to galvanise these efforts to stimulate widespread, pedagogically sound m-learning practices in teacher education and ultimately in schools.

\section{ACKNOWLEDGMENT}

The toolkit was developed using funding from the European Union under the Erasmus+ funding stream (2014-1-UK01-KA200-001796) 


\section{REFERENCES}

Adams Becker, S., Freeman, A., Giesinger Hall, C., Cummins, M., \& Yuhnke, B. (2016). NMC/CoSN Horizon report: 2016 K- (12th ed.). Austin, Texas: The New Media Consortium.

Baran, E. (2014). A review of research on mobile learning in teacher education. Journal of Educational Technology \& Society, 17(4), 17-32.

Botha, A., \& Herselman, M. (2015). A Teacher tablet toolkit to meet the challenges posed by 21 st century rural teaching and learning environments. South African Journal of Education, 35(4), 1-19. doi:10.15700/saje. v35n4a1218

Bowe, R., \& Winter, J. S. (2014). Creating a technology toolkit: Effects of a technology orientation during student teaching. In M. Searson, \& M. Ochoa (Eds.), Proceedings of SITE International Conference 2014 (pp. 2441-2446). Chesapeake, VA: AACE.

Burden, K., \& Hopkins, P. (2016). Barriers and challenges facing pre-service teachers' use of mobile technologies for teaching and learning. International Journal of Mobile and Blended Learning, 8(2), 1-20. doi:10.4018/ IJMBL.2016040101

Burden, K., \& Kearney, M. (2017). Investigating and critiquing teacher educators' mobile learning practices. Interactive Technology and Smart Education, 14(2), 110-125. doi:10.1108/ITSE-05-2017-0027

Campbell, A., \& Groundwater-Smith, S. (Eds.). (2007). An ethical approach to practitioner research: Dealing with issues and dilemmas in action research. London: Routledge.

Cochrane, T., \& Antonczak, L. (2014). Implementing a mobile social media framework for designing creative pedagogies. Social Sciences, 3(3), 359-377. doi:10.3390/socsci3030359

Conole, G., \& Fill, K. (2005). A learning design toolkit to create pedagogically effective learning activities. Journal of Interactive Media in Education, 2005(1).

Conole, G.C., \& Oliver, M. (2002). Embedding theory into learning technology practice with toolkits. Journal of Interactive Media in Education, 2002(2).

Dyckhoff, A. L., Zielke, D., Bültmann, M., Chatti, M. A., \& Schroeder, U. (2012). Design and implementation of a learning analytics toolkit for teachers. Journal of Educational Technology \& Society, 15(3), 58-76.

Gasparini, A. (2011). Touch, learn, play-what children do with an iPad in the classroom. University of Oslo, Masteroppgave. Retrieved March 1, 2017 from https://www.duo.uio.no/handle/10852/9015

Ghaye, A., \& Ghaye, K. (1998). Teaching and learning through critically reflective practice. London: David Fulton.

Goodwin, K., \& Highfield, K. (2013). A framework for examining technologies and early mathematics learning. In L. D. English \& J. T. Mulligan (Eds.), Reconceptualizing early mathematics learning (pp. 205-226). New York, NY: Springer. doi:10.1007/978-94-007-6440-8_11

Green, L. S., Hechter, R. P., Tysinger, P. D., \& Chassereau, K. D. (2014). Mobile app selection for 5th through 12th grade science: The development of the MASS rubric. Computers \& Education, 75, 65-71. doi:10.1016/j. compedu.2014.02.007

Herrington, J., Ostashewski, N., Reid, D., \& Flintoff, K. (2014). Mobile technologies in teacher education. In Successful Teacher Education (pp. 137-151). Rotterdam, Netherlands: SensePublishers.

Kearney, M., Burden, K., \& Rai, T. (2015). Investigating teachers' adoption of signature mobile pedagogies. Computers \& Education, 80, 48-57. doi:10.1016/j.compedu.2014.08.009

Kearney, M., Schuck, S., Burden, K., \& Aubusson, P. (2012). Viewing mobile learning from a pedagogical perspective. Research in Learning Technology, 20. doi:10.3402/rlt.v20i0/14406

Kemmis, S., \& McTaggart, R. (1988). The action research planner. Victoria: Deakin University Press. 
Lim, C. P., \& Pannen, P. (2012). Building the capacity of Indonesian education universities for ICT in preservice teacher education: A case study of a strategic planning exercise. Australasian Journal of Educational Technology, 28(6), 1061-1067. doi:10.14742/ajet.811

Naylor, A., \& Gibbs, J. (2015). Using iPads as a learning tool in cross-curricular collaborative initial teacher education. Journal of Education for Teaching, 41(4), 442-446. doi:10.1080/02607476.2015.1081718

Oliver, M., \& Conole, G. (2000). Assessing and enhancing quality using toolkits. Quality Assurance in Education, 8(1), 32-37. doi:10.1108/09684880010312677

Pachler, N., Bachmair, B., \& Cook, J. J. (2009). Mobile learning: Structures, agency, practices. New York: Springer.

Radinsky, J., Bouillion, L., Lento, E. M., \& Gomez, L. M. (2001). Mutual benefit partnership: A curricular design for authenticity. Journal of Curriculum Studies, 33(4), 405-430. doi:10.1080/00220270118862

Salomon, G., \& Perkins, D. (1998). Individual and social aspects of learning. Review of Research in Education, $23,1-24$.

Schuck, S., Aubusson, P., Kearney, M., \& Burden, K. (2013). Mobilising teacher education: A study of a professional learning community. Teacher Development, 17(1), 1-18. doi:10.1080/13664530.2012.752671

Schuler, C., Winters, N., \& West, M. (2012). The future of mobile learning: Implications for policy makers and planners. Paris: UNESCO.

Wang, M., \& Shen, R. (2012). Message design for mobile learning: Learning theories, human cognition and design principles. British Journal of Educational Technology, 43(4), 561-575. doi:10.1111/j.1467-8535.2011.01214.x

Wertsch, J. V. (1991). Voices of the mind: A sociocultural approach to mediated action. Cambridge, Mass: Harvard University Press.

Willis, J. (2000). The maturing of constructivist instructional design: Some basic principles that can guide practice. Educational Technology, 40(1), 5-16.

\section{ENDNOTES}

The International Mobile Learning Festival (IMLF), Hong Kong, 2015

In Germany, 2015 \& Norway, 2016 (see http://mttep.weebly.com/events.html)

e.g. The European Conference on Tech. Enhanced Learning (ECTEL), Toledo, 2015; M-Learning in Teacher Education (MITE) conferences 2015, 2016, 2017; The International Mobile Learning Festival, HK, 2015, 2016.

mLearn2016: World Conference on Mobile \& Contextual Learning, Sydney, Australia

e.g. Burden and Kearney (2017) 